\title{
Impact of wellness indicators on intellectual dimensions of medical teachers of Karachi: Findings from cross sectional study
}

\author{
Rehana Rehman \\ Aga Khan University, rehana.rehman@aku.edu \\ Sadiqa Syed \\ Princes Nourahbint Abdulrahman University, KSA. \\ Mehwish Hussain \\ Dow University of Health Sciences, Karachi, Pakistan \\ Tayyab Raza Fraz \\ University of Karachi, Karachi, Pakistan \\ Saif Ullah Shaikh \\ Bahria University Medical and Dental College, Karachi, Pakistan
}

Follow this and additional works at: https://ecommons.aku.edu/pakistan_fhs_mc_bbs

Part of the Life Sciences Commons, Medical Education Commons, and the Teacher Education and Professional Development Commons

\section{Recommended Citation}

Rehman, R., Syed, S., Hussain, M., Fraz, T. R., Shaikh, S. U. (2020). Impact of wellness indicators on intellectual dimensions of medical teachers of Karachi: Findings from cross sectional study. JPMA. The Journal of the Pakistan Medical Association, 70(4), 655-659.

Available at: https://ecommons.aku.edu/pakistan_fhs_mc_bbs/830 


\title{
Impact of wellness indicators on intellectual dimensions of medical teachers of Karachi: Findings from cross-sectional study
}

\author{
Rehana Rehman, ${ }^{\text {Sadiqa Syed, }}{ }^{2}$ Mehwish Hussain, ${ }^{3}$ Tayyab Raza Fraz, ${ }^{4}$ Saif Ullah Shaikh ${ }^{5}$
}

\begin{abstract}
Objective: To measure impact of social, spiritual, occupational, physical, financial and emotional wellness on intellectual wellness of medical teachers.

Methods: The cross-sectional study was conducted at 8 medical universities in the Sindh province of Pakistan from January 2012 to December 2014, and comprised faculty members. Using a self-administered questionnaire, teachers' responses on physical, emotional, social, spiritual, intellectual, occupational and financial spokes of the wellness wheel that were graded on a 4-point Likert scale. Generalised linear models were executed to find the best predictive scores for intellectual wellness.

Results: Out of 300 subjects approached, $261(87 \%)$ returned the questionnaire fully completed. Of them, $86(33 \%)$ were males and 175(67\%) were females. Occupational wellness followed by spiritual, financial and emotional wellness depicted significantly high correlation with IW $(p<0.05)$. Adjusted analysis revealed significant effects of spiritual, financial and occupational wellness $(p<0.05)$. Findings of Models 1 and 2 suggested that holding the effect of other wellness subscales, intellectual wellness increased up to 0.485 score and 0.245 score due to occupational and spiritual wellness $(p<0.05)$ respectively, while financial wellness was not significant $(p>0.05)$. In the final model, occupational wellness effect increased to 0.504 score and spiritual wellness effect projected to 0.273 score for intellectual wellness $(p<0.05)$.

Conclusion: Amongst all the spokes of the wellness wheel, occupational, financial, social, emotional and spiritual wellness improved mental capabilities of medical teachers to overcome the challenges for acquiring intellectual wellness. However, wellness at workplace played the major role in enhancing intellectual proficiencies.
\end{abstract}

Keywords: Intellectual wellness, Wellness wheel, Medical teachers, Prediction. (JPMA 70: 655; 2020) https://doi.org/10.5455/JPMA.19316

\section{Introduction}

Subjective well-being (SWB) is the central component in the evaluation of quality of life (QOL) of an individual, and refers to the perception of different life situations in broader psychological and social aspects. ${ }^{1}$ Certain factors influence state of wellness, including nutrition, physical activity, stress-coping methods, good relationships, and career success. The pursuit of health, personal growth, and improved QOL relies on living a balanced life. Wellness is the search for enhanced standard of life, personal growth, and potential through positive lifestyle behaviours and attitudes. ${ }^{2}$

Wellness matters because every aspect of life revolves around it in some way or the other. Intellectual wellness (IW) means having an open mind to new opportunities or

Department of Biological \& Biomedical Sciences Agha Khan University, Karachi, Pakistan, 2Department of Physiology, College of medicine, Princes NourahBint Abdul Rehman University, Riyadh, KSA, ${ }^{3}$ Research Department Dow University of Health Sciences, Karachi, Pakistan, ${ }^{4}$ Department of Statistics, University of Karachi, Karachi, Pakistan, 5 Department of Physiology, Bahria University Medical and Dental College, Karachi, Pakistan. Correspondence: Saif Ullah Shaikh. Email: dr.saif74@yahoo.com ideas and seeking new experiences that challenge a person both mentally and socially. ${ }^{3}$ Occupational wellness (OW) indicates finding and pursuing one's favourite carrier. ${ }^{3}$ Financial wellness (FW) represents keeping a successful balance between earning and expenses. ${ }^{4}$ Spiritual wellness (SpW) signifies finding hope, comfort and inner peace in one's own existence; anything that gives a sense of purpose in addition to religious deeds. ${ }^{5}$ Social wellness (SW) involves building a support system with friends, family and others that can be tested in times of need. ${ }^{6}$ Environmental wellness (EnW) includes an individual's study space, sleep space, living arrangements, and work environment. ${ }^{7}$ Physical wellness (PW) denotes maintaining a healthy body through physical activity, a healthy diet, and adequate sleep. ${ }^{8}$ Emotional wellness (EmW) designates the ability to understand positive and negative emotions and to develop strategy to cope with them and to express negative emotions in a productive manner. ${ }^{9}$

Keeping in mind the importance of all the spokes of the wheel of wellness, the fact that medical teachers are overworked with professional activities, including teaching undergraduate and postgraduate students, 
conducting and supervising research and publications, mentoring / advising activities, and administration responsibilities, makes them a group that needs to be studied in wellness terms. Furthermore, they are overwhelmed by emotional demands from the institution, the students as well as the parents. The current study was planned to observe the impact of all the spokes of wellness wheel on IW of medical teachers.

\section{Subjects and Methods}

The cross-sectional study was conducted at 8 medical universities in the Sindh province of Pakistan from January 2012 to December 2014, and comprised faculty members. Approval was obtained from the ethics review committee of Bahria University Medical and Dental College, Karachi, and permission was taken from the institutional head of each of the 5 private- and 3 public-sector medical universities. Convenience sampling was used to select the study sites. Faculty members were approached and enrolled using snowball / referral sampling. Teachers who were present at the time of the visit and agreed to participate were included. Principal, Director or any faculty member in position of administrative authority were excluded because the questionnaire focussed on teaching and research activities, and their inclusion might have led to selection bias.

After verbal informed consent from each participant, data was collected using a self-administered questionnaire that took 15-20 minutes to fill. The questionnaires returned were checked on the spot.

The questionnaire comprised two parts. The first part contained personal information, including gender, age in years, type of institute, duration of employment and monthly salary. The second part comprised wellness scale that had 55 items. ${ }^{10}$ The questionnaire was further classified into seven spokes which were PW 11 items, EmW 6 items, SW 7 items, SpW 6 items, IW 8 items, OW 13 items and FW 6 items. Each spoke further contained sets of relevant items based on a 4-point Likert scale with responses 1 as no/never, 2 as sometimes, 3 as usually and 4 as yes/always.

The questionnaire was pre-tested for reliability by a pilot study on 50 teachers. Reliability of the questionnaire was measured by Cronbach's alpha which was 0.7 , implying consistency in the responses.

It was hypothesized that IW is affected by other wellness dimensions, and, therefore, IW was kept as the dependent variable and the other 6 dimensions as independent variables. The responses in each dimension were added to get a composite physical, emotional, social, spiritual, intellectual, occupational and financial wellness.

The sample size was suitable for applying regression methods while considering 5 subjects per variable approach. ${ }^{11}$ Data was analysed using Stata 12. Frequencies with percentages were reported for defining personal characteristics of the subjects. Before proceeding towards inferential analysis, all wellness scores were checked for normality using Shapiro-Wilk's test and were found to be non-normal. Therefore, the correlation of IW with other subscales of the wellness wheel was computed using Spearman's correlation coefficient. Generalised linear models with logarithmic transformation were built and the best subset was detected on the basis of highly significant $P$ values of the variables. The prediction scores for IW were obtained by unadjusted and adjusted regression models. Three approaches were used to obtain the adjusted prediction models. First model was built while taking all the significant wellness subscales as predictors. Second model contained the predictors which showed high association in the analysis of correlation. Third model included those predictors which showed significance in model 1.

\section{Results}

Of the 300 faculty members approached, 261(87\%) returned the questionnaire completed; $160(\%)$ from private universities and 101(\%) from public-sector universities. Also, there were $86(33 \%)$ males and $175(67 \%)$ females. Also, 103(39.5\%) of the subjects were aged $<30$ years and $158(60.5 \%)$ were $>30$ years.

In terms of reliability consistency, responses related to overall wellness, OW, IW, SpW and PW were more reliable than EmW, FW and SW subscales (Table-1).

According to the findings of correlation analysis, OW depicted highest correlation with IW. SpW and FW also had positive and moderate correlations with IW. All the wellness subscales had positive relationship

Table-1: Reliability of wellness scale and its subscales.

\begin{tabular}{lcc}
\hline Scale & Cronbach's alpha & Decision \\
\hline Wellness & 0.828 & Good internal consistency \\
Physical & 0.639 & Acceptable internal consistency \\
Emotional & 0.456 & Poor internal consistency \\
Social & 0.349 & Poor internal consistency \\
Spiritual & 0.666 & Acceptable internal consistency \\
Intellectual & 0.713 & Acceptable internal consistency \\
Occupational & 0.755 & Acceptable internal consistency \\
Financial & 0.356 & Poor internal consistency \\
\hline
\end{tabular}


Table-2: Predicted models for intellectual wellness.

\begin{tabular}{|c|c|c|c|c|c|c|}
\hline MODEL & Scale & Coefficient & t value & p-value & Decision & R square \\
\hline \multirow[t]{6}{*}{ UNADJUSTED } & Spiritual & 0.413211 & 6.09 & $<0.01$ & highly significant & 0.125 \\
\hline & Occupational & 0.552655 & 11.93 & $<0.01$ & highly significant & 0.354 \\
\hline & Financial & 0.344882 & 5.56 & $<0.01$ & highly significant & 0.106 \\
\hline & Physical & 0.0524385 & 0.87 & 0.384 & insignificant & 0.002 \\
\hline & Emotional & 0.2567976 & 3.39 & $<0.01$ & highly significant & 0.042 \\
\hline & Social & 0.256877649 & 3.5 & $<0.01$ & highly significant & 0.045 \\
\hline \multirow[t]{5}{*}{ MODEL 1} & Emotional & -0.01475 & -0.2 & 0.845 & insignificant & 0.411 \\
\hline & Social & 0.079626 & 1.21 & 0.229 & insignificant & \\
\hline & Spiritual & 0.244766 & 3.4 & $<0.01$ & highly significant & \\
\hline & Occupational & 0.485644 & 9.49 & $<0.01$ & highly significant & \\
\hline & Financial & 0.044286 & 0.76 & 0.45 & insignificant & \\
\hline \multirow[t]{3}{*}{ MODEL 2} & Spiritual & 0.268429 & 4.63 & $<0.01$ & highly significant & 0.407 \\
\hline & Occupational & 0.489981 & 9.65 & $<0.01$ & highly significant & \\
\hline & Financial & 0.038431 & 0.67 & 0.505 & insignificant & \\
\hline & Occupational & 0.5047711 & 11.06 & $<0.01$ & highly significant & \\
\hline
\end{tabular}

\section{Correlation with Intellectual Wellness}
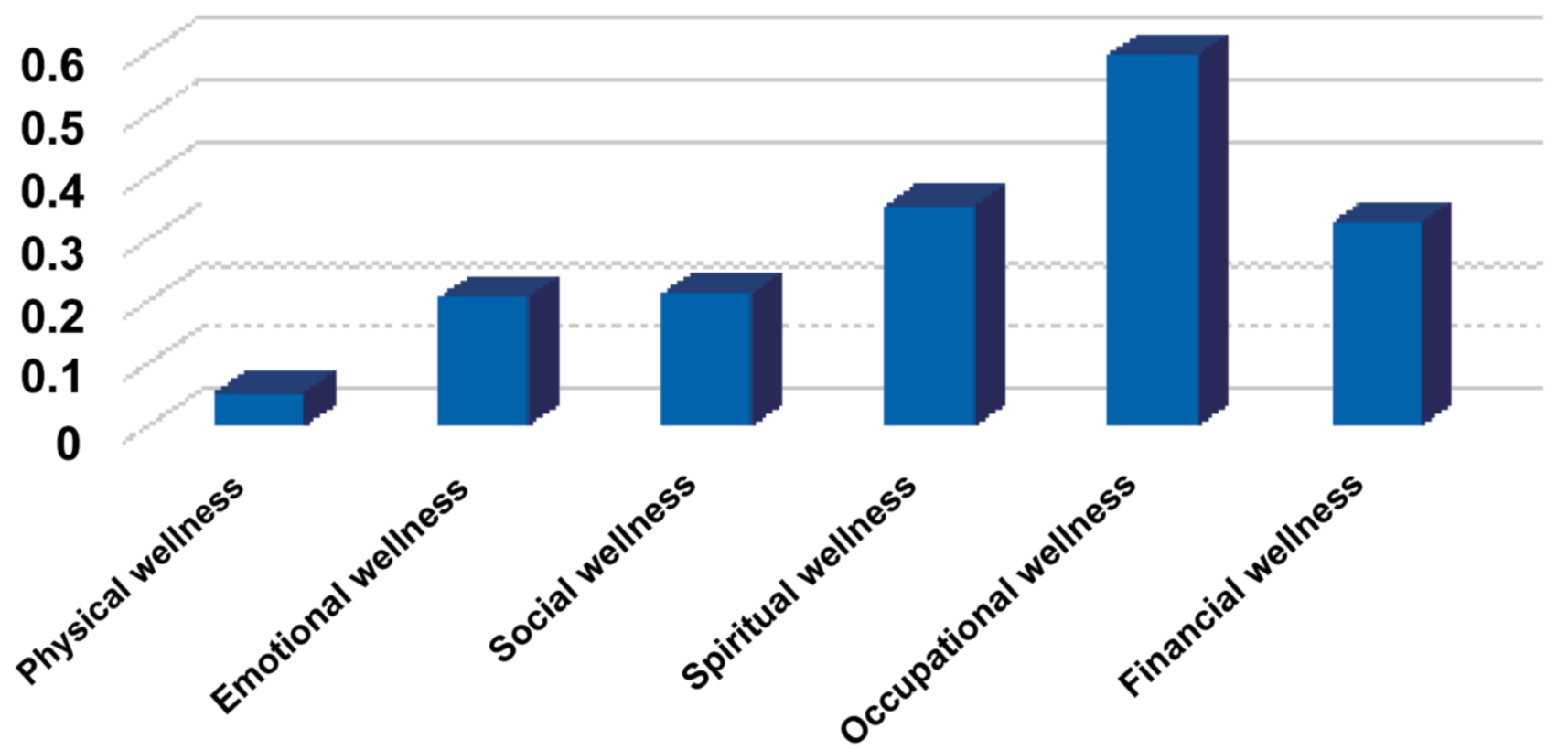

Figure: Correlation of different subscales of wellness with intellectual wellness.

with IW (Figure).

Unadjusted models, showed that an increase in SpW score increased IW by 0.413 . Similarly, an increase in OW score increased IW score by 0.5526 . FW had a positive impact on IW by 0.345 . EmW and SW had an impact of
0.257 , while PW did not produce any significant effect (Table-2)

Multivariable model kept all the significant predictors in model 1. Hence, EmW, SW, SpW, OW and FW scores were kept intact. Adjusted analysis revealed significant effects 
of only SW and OW $(\mathrm{p}<0.05)$. IW increased up to 0.485 and 0.245 due to OW and SpW respectively. Model 2 depicted significant values for OW and SpW $(p<0.05)$ and nonsignificant value for $\mathrm{FW}$. Model 3 retained the best predictors as significant, showing $\mathrm{OW}$ effect going up to 0.504 and SpW up to 0.273 score for IW.

\section{Discussion}

As teachers play an important role in shaping positive health behaviours in students, they should be aware of issues concerning QOL and preventive healthcare management Moreover, there are high levels of depression, anxiety and job dissatisfaction which raise concerns about the well-being of doctor-teachers. It is thus important to recognise the value of an individual's health in the broader aspects of various wellness dimensions. A study revealed that the overall assessment of wellness and QOL is most strongly associated with environment, psychological and social relationship domains. ${ }^{12}$ Another research showed that the subjective well-being is positively related with physical and mental health, performance on job, interpersonal relationships and marital status. ${ }^{13}$ A strong association of all dimensions of wellness with IW was found in our study, but OW and SpW predominantly affected IW.

Awareness of IW is important in the sense that it is a "a positive state of well-being which enables an individual not only to be able to function normally in society and meet the demands of everyday life, but also allows them to use logical and rational reasoning as well as critical thinking. ${ }^{9}$ Moreover, to be able to function normally in society and meet the demands of everyday life, people in good mental health have the ability to recover effectively from illness, change or misfortune."14 This can be explained on the basis of the observation that $80 \%$ of all diseases reported at the National Institute of Health were caused by accumulated, unmanaged stress indicating lack of EW, and lack of creative, recreational activities indicating low SW. 9 Results of our study show that emotional well-being enhanced IW which may help the individual to withstand hazards of stress and think of coping strategies to improve the intellectual capabilities. ${ }^{14}$

Although physical wellness had negligible impact on IW in the current study, impact of physical activity on healthrelated QOL was observed by other researchers. ${ }^{15}$ The idea of being associated with others is a universally inherent trait of human beings, emphasising the significance of social support from different individuals. SW is thus acquired in cooperation within or among groups of people. ${ }^{16}$ Moreover, it is an invisible force embedded in relationships of individuals, organisations, communities and economic indicators which support growth of society. ${ }^{17}$ The impact of social interdependence on IW of medical teachers is supported by a study that observed the role of friends and family members and mentors to improve the academic performance and selfesteem. ${ }^{18}$ We also recognised the importance of social relationships in the form of social networks, norms and values and its implications on IW as significant association was found between IW and SW. A few studies reported that lack of social connectedness is a strong predictor for the development of cardiovascular diseases ${ }^{19}$ cognitive deterioration 20 and mortality 21 than other traditional risks, but unfortunately social relationships in industrialised societies are decreasing. 22

A positive impact of SpW on IW was identified in the current study and is supported by an earlier study. ${ }^{23} \mathrm{~A}$ study supported the positive association of religious beliefs with good mental health, leading to overall positive progress in the academic performance of medical students. ${ }^{24}$ It is thus essential to promote and measure the development of SpW.

FW can be said to be 'high' when individuals have positive financial attitudes and exhibit healthy financial behaviour. The present study examined whether FW affected IW and observed a non-significant relationship between the two. Previous studies have confirmed that economic status strongly predicts happiness and overall well-being in most cultures. People are happier when they are financially secure. ${ }^{25}$ Consistent with earlier studies 26 we found that positive financial behaviours affected IW.

Results of the current study stressed that a congenial enabling workplace environment could nurture the intellectual capabilities of medical teachers. It can be possible only with support from all representatives of the organogram in the respective institution. Further, it is expected that an ideal workplace should promote monitored supervision with rewards and recognition to foster the worker skills and fulfill job demands, and achieve health and safety in the workplace. Thus, we hope that emotional climate and the prevailing atmosphere in medical colleges will deliver professional identity and development of professionalism.

Since the study was conducted in medical universities of Karachi alone, therefore generalisation of results for medical teachers in other universities is not recommended. However, the results have emphasised the importance of an enabling workplace environment to facilitate IW of all medical teachers in different universities of Pakistan. 


\section{Conclusion}

Among all the spokes of the wellness wheel, occupational, financial, social, emotional and spiritual components improved mental capabilities of medical teachers to overcome the challenges for acquiring IW. Nevertheless, wellness at workplace played the major role in enhancing intellectual proficiencies.

Disclaimer: None.

Conflict of Interest: None.

Source of Funding: This research was funded by the Deanship of scientific research at Princess Nourah bint Abdulrahman University through the Fast track research funding Program.

\section{References}

1 Renshaw TL, Long AC, Cook CR. Assessing teachers' positive psychological functioning at work: Development and validation of the Teacher Subjective Wellbeing Questionnaire. Sch Psychol Q. 2015; 30:289-306.

2 Rehman R, Syed S, Hussain M, Shaikh S. Health and Spirituality" walk along" in wellness journey of medical students. J Pak Med Assoc. 2013; 63:495-500.

3 Syed S, Rehman R, Hussain M, Shaikh S. Intellectual wellness in medical university teachers: Gender based comparison. J Pak Med Assoc. 2017; 67:782-4.

4 Waddell R. Financial wellness. [Online] [Cited 2014 August 21].

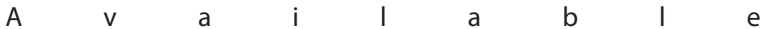
from:URL:http://www.lincoln.wrfa.com/FinancialWellness.6.htm

5 Craigie JF. Spiritual perspectives and practices of family physicians with an expressed interest in spirituality. Fam Med. 1999; 31:578-85.

6 Rehman R, Katpar S, Hussain M, Khan R, Baig M. A comparison between wellness awareness among medical students. J Pak Med Assoc. 2017; 67:196-9.

7 Katpar S, Khan R, Siddiqu R, Hussain M, Rehman R. Perceptions of medical students regarding dimensions of environmental wellness. J Pak Med Assoc. 2016; 66:373-7.

8 Furmonavicius T, Petkeviciene RT. Influence of lifestyle, biological and other factors on subjective evaluation of physical functioning. Medicina (Kaunas). 2002; 38:1224-9.

9 Rehman R, Nadeem S, Hussain M, Khan R, Katpar S. Exploring emotional wellness: The art of being cheerful about life at medical campus. Eur J Psychol Educ Studies. 2015; 2:57-62.

10 Vanderbilt University. Wellness resource centre. [Online] [Cited
2009 November 04]. Available from URL: www.Vanderbilt.Edu/wellnesscenter/wellness wheel.html

11 Austin PC, Steyerberg EW. The number of subjects per variable required in linear regression analyses. J Clin Epidemiol. 2015; 68:627-36.

12 Baceviciene M, Reklaitiene R. Psychometric properties of the World Health Organization Quality of Life 100 questionnaire in the middle-aged Lithuanian population of Kaunas city. Medicina (Kaunas) 2009; 45:493-500.

13 Sirgy MJ, Michalos AC, Ferriss AL, Easterlin RA, Patrick D, Pavot W. The quality-of-life (QOL) research movement: Past, present, and future. Social Indicators Research. 2006; 76:343-466.

14 Naz AS, Rehman R. Medical students' endeavour to make use of their mental capabilities. J Pak Med Assoc. 2013; 63:568-72.

15 Brown DW, Brown DR, Heath GW, Balluz L, Giles WH, Ford ES, et al. Associations between physical activity dose and health-related quality of life. Med Sci Sports Exerc. 2004; 36:890-6.

16 Healy T, Côté S. The Well-Being of Nations: The Role of Human and Social Capital. Education and Skills. OECD, 2 rue Andre Pascal, F75775 Paris Cedex 16, France; 2001.

17 Schiuma G, Lerro A, Sanitate D. The intellectual capital dimensions of Ducati's turnaround: exploring knowledge assets grounding a change management program. Inter J Innov Management. 2008; 12:161-93.

18 Rehman R, Habib M, Fatima SS. A take on social wellbeing attributes by first year medical students. J Pak Med Assoc. 2014; 64:679-82.

19 Barth J, Schneider S, Von Känel R. Lack of social support in the etiology and the prognosis of coronary heart disease: a systematic review and meta-analysis. Psychosom Med. 2010; 72:229-38.

20 Bassuk SS, Glass TA, Berkman LF. Social disengagement and incident cognitive decline in community-dwelling elderly persons. Ann Inter Med.1999; 131:165-73.

21 Heffner KL, Waring ME, Roberts MB, Eaton CB, Gramling R. Social isolation, C-reactive protein, and coronary heart disease mortality among community-dwelling adults. Soc Sci Med. 2011; 72:1482-8.

22 McPherson M, Smith-Lovin L, Brashears ME. Social isolation in America: Changes in core discussion networks over two decades. Am Soc Rev. 2006; 71:353-75.

23 Seaward BL. Reflections on human spirituality for the worksite. Am J Health Promot. 1995; 9:165-8.

24 Nazir S, Malik S. Workplace spirituality as predictor of workplace attitudes among Pakistani doctors. Am J Health Promot. 1995; 9:165-8.

25 Lyubomirsky S, Sheldon KM, Schkade D. Pursuing happiness: the architecture of sustainable change. Rev Gen Psychol. 2005; 9:111 31.

26 Shim S, Xiao JJ, Barber BL, Lyons AC. Pathways to life success: A conceptual model of financial well-being for young adults. J Appl Dev Psychol. 2009; 30:708-23. 